\title{
POST-NATAL REHABILITATION
}

\author{
B) ROSEMARYY HARTE, M.C.S.P.
}

$\mathbf{I}^{\mathrm{N}}$ MY opinion, the ideal is to start within a few hours of the birth of the baby. Unfortunately the average physiotherapist has no access to the patient at this stage, but those mothers who have attended pre-natal classes may have instruction with demonstrations.

When this is possible, there are four simple exercises which should not unduly tax any normal patient, whether or no she has stitches. The psychological effect is very considerable, the patient realising that it is up to her to rehabilitate herself, and the mental and physical stimulation brings remarkable rewards. I am now referring to private patients, where very often the physiotherapist does not feel justified in committing the patient to a visiting fee for a very short treatment in the first two days. Where the patient is in an institution where routine physiotherapy is provided, this is naturally carried out from the first day.

The four exercises referred to are:

(1) Crook lying, knees squeezing together, tightening the glutei and drawing up the pelvic floor. I usually teach this with a sucking in of the abdominal-wall (not an abdominal contraction) in the hopes that the partial vacuum caused in the abdomen may help to draw up the pelvic fioor.

(2) Crook lying, abdominal breathing with abdominal contractions. This exercise works the straight abdominal muscles in their entire range. Care must be taken to see that the patient flattens her spine into the bed until the Recti become taut, at the finish of the exercise. Too often patients feel they are tightening their abdominal muscles when they suck them in as in exercise 1 , which has no value as an abdominal exercise since it is, in effect, stretching them concavely.

(3) Lying with ankles crossed, squeezing knees together, tightening glutei and sucking in abdomen while pulling up the pelvic floor. Similar to number 1, but with a slight difference in the stress of the muscles.

(4) Lying with arms -folded, or to the side, head and shoulder raising. This is a strong abdominal muscle exercise.

If these exercises are carried out conscientiously, (a little and often throughout the day being preferable to one daily session to the point of fatigue), the effects should be:

(1) When the mother first gets up, she should in some measure, be able to control her abdominal 'muscles.

(2) The average patient who has done no exercises will tell you that on first rising she feels as if she had "a large hole in her nether end through which her inside was prepared to drop at any moment." That sensation, plus overstretched abdominal muscles produce that gait peculiar to women who have just delivered . . . rather hunched, with knees pressed together and hands clasped firmly to the protruding abdomen. They seem quite incapable of walking naturally. This should be obviated if these exercises have been conscientiously done.

(3) Should the patient be left with some measure of stress incontinence, she should be able to alleviate it, and possibly cure it completely herself.

In the good old days when the patients lay abed for ten days, it was advisable to give exercises for the toes, ankles and quadriceps as well. In these enlightened days of early rising, I personally feel that this is unnecessary.
Now we come to the debatable subject of binders. Binders appeared to go out when early rising came in, and I can elicit no satisfactory reason from doctors. One even did me the honour of trying them out on several patients, but stated that it was quite unsatisfactory as they rolled into a little bunch in the waist in less time than the telling. Other doctors, no doubt, have a shrewd suspicion that if a patient wears a binder, she relaxes her abdominal wall against it, with a sigh of relief, and takes no further part in the re-education of her muscles.

My ideas on the subject are here for your acceptance or rejection.

(1) I am definitely in favour of them providing they are of the two-way stretch variety which can better bef controlled than calico, linen, etc.

(2) I would only sanction their use providing the patient were intelligent and had been instructed that they were an adjunct to exercises and not to be used instead of them. This is most important.

(3) If the abdominal muscles are stretched, it is much easier to work them hard in the important inner range, when they are supported some of the way.

(4) Even with a conscientious patient, the amount of time per day taken up with exercises is extremely small in a 24-hour day. When the patient is not doing her exercises, they are probably hanging or lying in an overstretched position, which I consider bad.

On or after the third day, the patient should be ready for full treatment, having laid the foundation herself. I know that some people think that exercises alone are sufficient, but, having given the matter much thought, I feel that abdominal massage in the first ten days is so beneficial that it should not be omitted if possible. It is very stimulating to the circulation, reflexly affecting the tone of the muscles and colon, and helping constipation which is so often present. A little special attention to the uterus helps to empty it and furthers involution. I do not consider that massage to the limbs is necessary if the patient has been allowed up early, neither do I feel that, if abdominat massage has been given in the first two weeks, it is of very great benefit after that. Exercises alone should then suffice.

Occasionally one is asked to massage for engorged breasts, a lengthy process if the breasts are to be emptied, but more often than not the nursing staff consider it their prerogative.

Exercises being the most important factor, these are progressed daily according to the capacity of the patient, and include work for the straight and oblique abdominal muscles, the pelvic fioor, posture and the breasts. I am not going to bore you with a detailed description of these exercises, they are too familiar to the average physiotherapist. By the 8th or 9th day the patient should be doing a full scheme of exercises, the benefit of which cannot be overstated. It is interesting to hear the opinions of patients who have had babies with and without treatment. They consider there is no comparison. They go home feeling fit and able to cope with a new baby and housework without that ghastly sense of fatigue which limits their activities and causes a certain amount of depression. 
While in the hospital, the nursing staff usually instruct the patients as a matter of routine, to spend a certain amount of their rest period in the prone lying position. The physiotherapist should check and see that this is being done.

As regards physiotherapy after a Caesarian section, I feel that these patients need it more than any others, as their period of rehabilitation is more protracted. An experienced physiotherapist can help them enormously in the first few days with very gentle abdominal massage to help dispel flatus, and carefully graded exercises, starting with static abdominal contractions. One must remember that psychologically these patients start at a disadvantage, and very often treatment dispels their vision of themself as a very sick person who must lie quite still for days. Their abdominal muscles and posture need far more re-educating than those of the woman who has delivered normally, and yet, funnily enough, these are the patients we see least of in practice.

If there are facilities, patients can start class work at a month to six weeks. I find if left to themselves, they seldom do their exercises at home, and the stimulation and competition of class work appeals to them. On the other hand a large percentage cannot make suitable arrangements for leaving their babies, and it should be stressed that in this case, they must work at home if they wish to complete the treatment.

In conclusion, I would like to say that I feel that postnatal treatment should be routine in obstetrics, but I do realise that there is a financial side to it in private practice, which sometimes defeats its own ends.

\section{Deliverance ...}

from pain... the humanitarian function of of the practitioner. . . . now accomplished with greater speed, more economy and with a higher degree of safety than ever before.

Full details and clinical notes on the use of

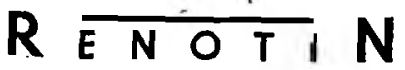

in the treatment of Migraine, Neuritis, Lumbago, Sprains and Myalgia may be obtained from

Exclusive Distributors for Southern Africa'

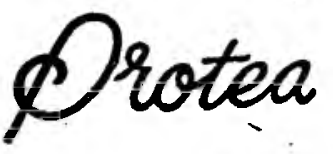

PHARMACEUTICALS LTD.

P.O. BOX 7793

JOHANNESBURG

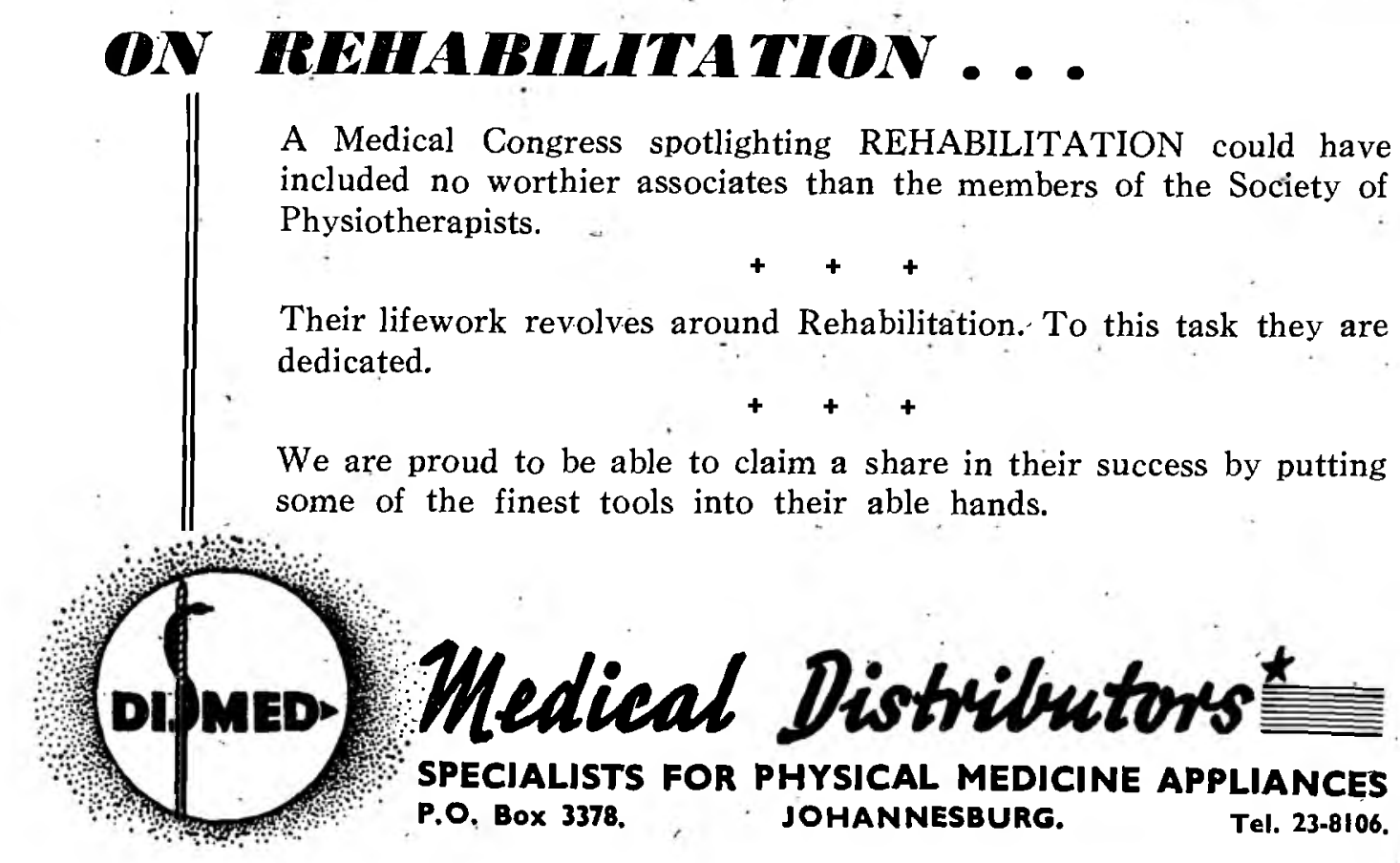

Telegraphic Address: "DISMED.".

Office and Showroom at 236, JEPPE STREET. 